\title{
Didier LETT et Marie-France MOREL, Une histoire de
}

l'allaitement

Paris, Éditions de la Martinière, 2006, 159 pages

Mathilde Dubesset

\section{OpenEdition}

Journals

Édition électronique

URL : http://journals.openedition.org/clio/9730

DOI : 10.4000/clio.9730

ISSN : 1777-5299

Éditeur

Belin

Édition imprimée

Date de publication : 1 mai 2010

ISSN : 1252-7017

Référence électronique

Mathilde Dubesset, "Didier Lett et Marie-France morel, Une histoire de l'allaitement », Clio. Femmes,

Genre, Histoire [En ligne], 31 | 2010, mis en ligne le 17 juin 2010, consulté le 21 septembre 2020. URL

http://journals.openedition.org/clio/9730 ; DOI : https://doi.org/10.4000/clio.9730

Ce document a été généré automatiquement le 21 septembre 2020.

Tous droits réservés 


\title{
Didier LETT et Marie-France MOREL, Une histoire de l'allaitement
}

Paris, Éditions de la Martinière, 2006, 159 pages

\author{
Mathilde Dubesset
}

1 Fruit d'une collaboration entre deux spécialistes de l'histoire de la naissance et de l'enfance, pour le Moyen Âge et l'époque moderne, ce livre doit à Caroline Lefebvre une très belle iconographie. L'allaitement: une scène, des gestes dont les représentations sont nombreuses et variées à travers le temps, comme le montre cet ouvrage de belle facture qui s'organise en cinq chapitres. On y découvre la richesse et la diversité des images autour d'une pratique universelle qui s'inscrit dans l'histoire des sociétés. L'allaitement est présenté ici comme un fait culturel dont les représentations doivent être interrogées, déchiffrées; c'est le sens des "arrêts sur image ", qui ponctuent le livre. « Depuis la nuit des temps, les hommes ont éprouvé le besoin de représenter les gestes de la lactation» (p. 7). Dans les sociétés anciennes, le lait maternel, comme le sang et le sperme, a une forte valeur symbolique. Les statuettes de déesses allaitantes, largement diffusées dans l'Égypte ancienne et l'Empire romain, ont une fonction de protection des femmes et des enfants. Le sein nourricier confère alors aux femmes une forme de puissance.

2 La figure de la Vierge Marie allaitant l'enfant Jésus est très présente dans l'iconographie de la fin du Moyen Âge, quand l'accent est mis sur l'humanité du Christ. La Vierge est aussi nourrice de l'humanité et son lait est parfois considéré comme un équivalent du sang du Christ. Cette représentation de "Maria Lactans" tend à disparaître au XVIII ${ }^{e}$ siècle ; le sein découvert de la Vierge serait-il devenu choquant? La peinture profane reprend alors le thème avec des figures de mères allaitantes aux allures de Madone.

3 Les allaitements marginaux, prodigieux ou allégoriques, nous introduisent dans un univers de représentations parfois surprenantes. Au Moyen Âge, le geste de refus du sein maternel de la part de saints, dans la prime enfance, est sans doute lié à la nécessité d'une rupture avec les femmes et la parenté, pour accéder à la sainteté. Saint Mamant, protecteur des mères qui allaitent, peut lui aussi nourrir un enfant au sein ; 
fantasme masculin d'appropriation d'une faculté propre aux femmes, réponse concrète à la hantise de la faim ? La femme donnant le sein est aussi allégorie : dans une version profane, c'est l'allégorie de la Grammaire; dans une version religieuse, celle de la Charité. Au XVII ${ }^{\mathrm{e}}$ siècle, temps de la Réforme catholique, le thème de la «charité romaine » est à l'honneur dans des tableaux montrant l'allaitement d'un adulte, parfois âgé, nourri par une jeune femme: une scène à forte connotation religieuse qui sera perçue, par la suite, d'une tout autre manière.

4 La pratique quotidienne de l'allaitement offre une gamme variée de croyances, de comportements et de situations au long des siècles, même si le thème de la supériorité de l'allaitement maternel traverse le temps, avec des arguments différents selon les époques. La scène de l'allaitement est parfois présentée comme l'occasion, pour les mères, d'être traitées avec des égards particuliers, comme le suggère une image du XV ${ }^{\mathrm{e}}$ siècle: Joseph préparant la bouillie du premier jour pendant que Marie allaite (p. 91). Ambroise Paré, au XVI ${ }^{e}$ siècle, évoque même la jouissance physique que peut éprouver celle qui allaite. Ces représentations ne doivent cependant pas masquer les contraintes qui pesaient sur des femmes dont une partie de l'existence était soit «aux œufs » (être enceinte) soit « au lait» (allaiter). Si l'attention à l'alimentation de la mère et au risque provoqué par des émotions fortes susceptibles de gâter son lait est un thème récurrent, des changements s'opèrent au XX $\mathrm{XX}^{\mathrm{e}}$ siècle avec la fin de l'allaitement de longue durée et le recul de la mise en nourrice.

5 La mise en nourrice, pratique connue depuis l'Antiquité, peu répandue jusqu'à la fin du Moyen Âge, a pris une dimension importante dans la France de l'époque moderne. L'hypothèse du désintérêt pour l'enfant est discutable quand on observe de près le fonctionnement de la société et de ses codes. Les nourrices ont une place dans l'iconographie moderne et contemporaine, qu'elles s'occupent des enfants des élites (Gabrielle d'Estrées au bain, tableau vers 1598, p. 103) ou de ceux des milieux plus modestes (Nounous bretonnes, carte postale, 1910, p. 101). La diffusion de la mise en nourrice des enfants de la société urbaine, dans la France des $\mathrm{XVII}^{\mathrm{e}}$-XVIII ${ }^{\mathrm{e}}$ siècles, phénomène longtemps attribué au travail des épouses du monde de la boutique et de l'artisanat, est très liée à la spécificité du mode de vie urbain où l'on imite les usages des élites. L'offre importante de nourrices, dans des campagnes très peuplées, a pu susciter la demande des urbains, à la recherche du «bon air " pour leurs nourrissons. À la fin du XVIII ${ }^{e}$ siècle, les critiques des médecins face à la forte mortalité des enfants placés en nourrice, incitent des femmes de milieux nobles et bourgeois, souvent lectrices de Jean-Jacques Rousseau, à allaiter elles-mêmes leurs enfants. Le recours à la nourrice demeure cependant la norme dans les élites du XIX ${ }^{e}$ siècle, mais cette fois avec des nourrices « sur lieux ». La mise en nourrice s'essouffle au début du $\mathrm{XX}^{\mathrm{e}}$ siècle et la guerre de 1914-1918 accélère son déclin.

6 Le $\mathrm{XX}^{\mathrm{e}}$ siècle inaugure le temps des biberons, mais le recours à des substituts à l'allaitement maternel est très ancien. C'est l'allaitement animal présent dans la mythologie (Romulus et Remus nourris par une louve), dans les récits médiévaux : Saint Gilles allaité par une biche, tableau du XV $\mathrm{XV}^{\mathrm{e}}$ siècle (p. 135). Au XIX ${ }^{\mathrm{e}}$ siècle, ce sont des chèvres qui alimentent les bébés de l'Hospice des Enfants Assistés de Paris (p. 132). Tout un imaginaire s'est développé autour de ce mode d'allaitement qui précède l'avènement du biberon. Celui-ci a pu exister sous des formes diverses. Si les XVII ${ }^{\mathrm{e}}$ et $\mathrm{XVIII} \mathrm{I}^{\mathrm{e}}$ siècles ont connu les biberons en étain (dangereux à cause du plomb), c'est au $\mathrm{XIX}^{\mathrm{e}}$ siècle, grâce au caoutchouc et aux progrès en matière d'asepsie, qu'apparaissent 
les biberons modernes qui permettent l'allaitement «artificiel ». Le biberon, alternative à l'allaitement maternel et au recours à la nourrice est alors synonyme de modernité. Fortement recommandé par la puériculture américaine dans les années 1930, il contribue à une discipline de l'allaitement encouragée par des médecins, soucieux d'hygiène et de rationalisation, qui préconisent des horaires très réguliers pour l'allaitement (artificiel ou naturel), en rupture avec les pratiques traditionnelles.

7 Ce livre d'art et d'histoire, d'une lecture très agréable, rend compte de la polysémie des représentations de l'allaitement, objet d'histoire à part entière qui permet d'enrichir le regard porté sur l'histoire de la maternité et de l'enfance. L'iconographie de l'allaitement se raréfie au $\mathrm{XX}^{\mathrm{e}}$ siècle, période de recul global de l'allaitement maternel, mais celui-ci demeure un enjeu pour aujourd'hui. La question stimulante posée dans la conclusion en témoigne (p. 158) : "Alors que le ventre des femmes enceintes s'affiche avec détermination, pourquoi, au $\mathrm{XXI}^{\mathrm{e}}$ siècle, la vue d'une femme allaitant en public est-elle devenue inconvenante?». 